DOI: $10.47460 /$ uct.v24i107.412

\title{
APLICACIÓN DE BACTERIAS ÁCIDO-LÁCTICAS PROVENIENTES DEL MUCILAGO DE CACAO COMO AGENTE DE CONSERVACIÓN DE LA PAPAYA
}

\author{
Erazo Solórzano Cyntia ${ }^{1}$, Salazar Daza Diana ${ }^{2,}$ Vera Chang Jaime ${ }^{3}$, Tuárez García Diego ${ }^{4}$, \\ $\left\{\right.$ cerazo $^{1}$, diana.salazar2013 ${ }^{2}$, jverac $^{3}$, dtuarez $\left.{ }^{4}\right\}$ uteq.edu.ec \\ ORCID $^{1}$ : https/orcid.org/0000-0002-3942-7808, ORCID²: https/orcid.org/0000-0003-1756-1296, \\ ORCID ${ }^{3}$ : https/orcid.org/0000-0001-6127-2307, ORCID4: https/orcid.org/0000-0001-5153-1889 \\ Universidad Técnica Estatal de Quevedo \\ Quevedo - Ecuador.
}

Recibido (04/10/20), Aceptado (23/11/20)

\begin{abstract}
Resumen: El objetivo de esta investigación fue evaluar la conservación de la papaya con aplicación de bacterias ácidos lácticas provenientes del mucilago de cacao, se utilizaron diferentes porcentajes de aplicación $(0,5,10 \%)$ por aspersión a temperatura ambiente $35^{\circ} \mathrm{C}$, se valoró el cambio en las características físicas, químicas, y microbiológicas en un lapso de 14 días, el peso de la papaya fluctuó entre $1-1.4$ $\mathrm{kg}$, considerando una madurez de cosecha. Se realizó un Diseño Completamente al Azar (DCA) con arreglo bifactorial $\mathrm{AxB}$, para la comparación de medias de los tratamientos a estudiar se utilizó la prueba de rangos de Tukey al 5\%. Las variables evaluadas ( $\mathrm{pH}$, pérdida de peso, acidez) dio como resultado que el tratamiento T9 (10\% BAL; 14 Días) fue el que mantuvo mejores propiedades de almacenamiento transcurrido el tiempo de 14 días de conservación, el color de la fruta se mantuvo en niveles adecuados.
\end{abstract}

Palabras Clave: Características sensoriales, frutas frescas, procesamiento de frutas, tiempo de vida útil.

\section{APPLICATION OF LACTIC ACID BACTERIA FROM COCOA MUCILAGE AS A PRESERVATIVE AGENT FOR PAPAYA}

\begin{abstract}
The objective of this research was to evaluate the conservation of papaya with application of lactic acid bacteria from cocoa mucilage, different application percentages $(0,5,10 \%)$ were used by spraying at room temperature $35^{\circ} \mathrm{C}$, the change in physical, chemical, and microbiological characteristics in a period of 14 days, the weight of papaya fluctuated between $1-1.4 \mathrm{~kg}$, considering a harvest maturity. A Completely Random Design (DCA) was carried out with a bifactorial AxB arrangement, for the comparison of means of the treatments to be studied, the Tukey rank test at $5 \%$ was used. The variables evaluated ( $\mathrm{pH}$, weight loss, acidity) resulted in the T9 treatment (10\% BAL; 14 Days) that maintained the best storage properties after the 14-day storage time, the color of the fruit was kept at adequate levels
\end{abstract}

Keywords: Sensory characteristics, fresh fruits, fruit processing, shelf life. 


\section{I.INTRODUCCIÓN}

Ecuador exporta 69 tipos de frutas, entre las principales además del banano están, mango, piña, papaya, melón, guayaba, limón, frutillas, entre otras. Las exportaciones se están expandiendo a mercados internacionales muy competitivos y que exigen productos de excelente calidad. La agricultura y en el caso específico el producto papaya enfrenta problemas como la falta de nuevas tecnologías, financiamiento, conocimiento técnico, altibajo en la comercialización y ataque de plagas y enfermedades lo que lleva a limitarnos y tener pérdidas considerables de producción.

La reducción de las altas pérdidas de frutas y hortalizas requiere la adopción de varias medidas durante la cosecha, el manipuleo, el almacenamiento, el envasado y el procesamiento de frutas y hortalizas frescas para obtener productos adecuados con mejores propiedades de almacenamiento [1].

En la actualidad ha surgido la necesidad de buscar alternativas para conservar frutas debido a la naturaleza perecible que poseen. La demanda de los productos frescos mínimamente tratados esta aumentado en el mundo, así mismo el interés por emplear agentes antimicrobianos de origen natural, en tal sentido, la industria de las frutas demanda la combinación de dos o más factores que, interactúen aditiva y sinérgicamente para controlar poblaciones microbianas, cabe señalar que la velocidad de deterioro microbiológica no solo depende de los microrganismo presentes, sino también de la combinación química del producto y del tipo de carga microbiana inicial [2].

La industria alimentaria por tratar de satisfacer las exigencias de los consumidores ha impulsado el desarrollo y diseño de nuevas tecnologías, equipos, procesos y metodologías que permitan obtener productos con características semejantes a los alimentos frescos y con una vida útil equiparable a productos procesados. Las nuevas tecnologías ofrecen productos en su estado más natural, aumentan la vida de anaquel y sobre todo productos inocuos, al reducir significativamente la carga microbiana, sobre todo los considerados patógenos y de putrefacción de los alimentos [3].

Las películas y los recubrimientos comestibles se caracterizan por actuar como una barrera frente a la transmisión de humedad, solutos o gases. Brindan protección mecánica, poseen una determina solubilidad en agua, son transparentes, no otorgan sabor, ni olor diferente al alimento y no son detectados durante su consumo. Además, deben estar libre de tóxicos y ser seguros para el consumo humano, la tecnología necesaria para la producción debe ser sencilla y de bajo costo [4].

Los nuevos estilos de vida y la necesidad de reducir el tiempo de preparación de los alimentos, han provocado un aumento en el consumo de alimentos listos para el consumo, especialmente vegetales frescos mínimamente procesados [5]. Los beneficios de la tecnología poscosecha en la papaya beneficia desde el comerciante o expendedor de frutas hasta el consumidor final, prolongando el tiempo de distribución, dando solución a enfermedades causadas por hongos, que contribuyen al perecimiento de la fruta, de tal manera que eviten pérdidas poscosecha, beneficiando la economía y productividad [6].

El empleo de recubrimientos comestible a base de polisacáridos mejora la calidad de la papaya recién cortada [7], este recubrimiento ayuda a prevenir el daño físico, mejora el aspecto y reduce la flora microbiana, entre otros, logrando un mayor tiempo de conservación, sin efectos nocivos para la salud humana. Este recubrimiento procede del mucílago de cacao. Según [8], se denomina "almendra mucilaginosa" a la almendra fresca obtenida del fruto al abrir la mazorca de cacao, por lo que se refiere a la membrana de color blanco que recubre el grano. Previo a la fermentación del grano en cajas, el mucílago es desechado, considerándose por los agricultores un desperdicio.

Las bacterias ácidas lácticas BAL, son un grupo de microrganismos representadas por diversos géneros con características fisiológicas, metabólicas y morfológicas en común. En general las BAL son coco o bacilos Gram positivos, no esporulados, no móviles, anaeróbicos microaerofilicos, aero tolerantes; oxidasa, catalasa y benzidina negativas, que carecen de citocromos, no reducen ni el nitrato a nitrito y estos producen acido lácticos como el principal o único producto de la fermentación de los carbohidratos [9].

\section{II.DESARROLLO}

En una investigación realizada en México, se evaluó el efecto de un recubrimiento comestible a base de carboximetilcelulosa y adicionado con extracto etanólico de epazote sobre el control de Fusarium oxysporum, Colletotrichum gloeosporioides, Botrytis cinérea y Alternaria alternata en papaya Maradol, evidenciándose una reducción del $62.71 \%$ en la severidad de la enfermedad, mostrando que el extracto tiene una posible aplicación en recubrimientos comestibles para el control de enfermedades poscosecha. [10]

En otro estudio realizado para encontrar una estrategia efectiva en controlar la maduración de papaya Maradol, se evaluó la respuesta de los frutos a la aplicación de $300 \mathrm{~nL}$ L-1 del inhibidor 1-metilciclopropeno (1-MCP) y de $2.5 \mathrm{~g} \mathrm{~L}-1$ del inductor ácido 2-cloroetil fosfónico (etefón). En frutos cosechados en estado de 
madurez 1/4. Se aplicaron, 1-MCP, etefón, 1-MCP+etefón y etefón+1-MCP. La combinación etefón+1-MCP fue una estrategia efectiva para inducir la maduración sin ablandamiento extensivo de frutos, lo que permitió extender la vida útil de papaya Maradol [11].

La aplicación de películas comestibles biodegradables es otra alternativa para conservar y extender la vida útil de la papaya, como es el caso del estudio realizado en Brasil donde se evaluó el efecto de una película de almidón de yuca (2\%) sobre la papaya almacenadas a temperatura ambiental $\left(25 \pm 2{ }^{\circ} \mathrm{C}\right)$ y a $8{ }^{\circ} \mathrm{C}$, y $82 \%$ de humedad relativa durante 6 días de almacenamiento, presentado buenos resultados la almacenada a temperaturas refrigeración, en relación al $\mathrm{pH}$, grados Brix, acidez y carotenoides; y en la pérdida de peso [12].

Además, estudios realizados en Ecuador, empleando recubrimiento comestible a partir de aloe vera en papaya, utilizando diferentes porcentajes $(30 \%, 50 \%$ y $70 \%)$, en dos temperaturas de almacenamiento $\left(4^{\circ} \mathrm{C}\right.$ y $10^{\circ} \mathrm{C}$ ). Produjo resultados que extendieron el tiempo de vida útil por 10 días, en concentración del $70 \%$ de aloe vera y $10^{\circ} \mathrm{C}$ en temperatura de almacenamiento [13].

\section{III.METODOLOGÍA}

La investigación se realizó en el laboratorio de Rumiología de la Universidad Técnica Estatal de Quevedo, las muestras de cacao de origen trinitario CCN51, donde se extrajo el mucílago y las muestras de papaya fueron obtenidas en fincas del Cantón Mocache, ambas localidades situadas en la provincia de Los Ríos.

El trabajo experimental fue necesario hacerlo en dos fases, la primera el aislamiento de BAL y la segunda correspondiente a la disolución y aplicación sobre la fruta.

Para efectuar el aislamiento de las BAL se empleó mazorcas de cacao de origen Trinitario, se clasificaron según su estado de maduración, libre de agentes extraños y sin rastro de enfermedades propias del cultivo, se realizó la desinfección de las mazorcas con una solución al 60 ppm de cloro. Luego se cortaron las mazorcas y se extrajo con la ayuda de un lienzo, se presionó de tal manera que se exude la sustancia mucilaginosa que contienen de manera natural las mazorcas de cacao.

Se fermentó el mucílago en un recipiente libre de cualquier impureza o material extraño por un periodo de 24 horas a temperatura ambiente $\left(35^{\circ} \mathrm{C}\right)$, en este punto se efectuó análisis de $\mathrm{pH}$, utilizando un potenciómetro digital, la acidez titulable se determinó aplicando la NTE INEN-ISO 750 [14], los sólidos solubles fueron determinados con un refractómetro digital a $25^{\circ} \mathrm{C}$ y expresados en ${ }^{\circ}$ Brix, las determinaciones se realizaron por triplicado. Posteriormente el mucilago fermentado se sembró en MRS AGAR (LACTOBACILLUS MRS
AGAR) mediante el método extensión a una temperatura de $35^{\circ} \mathrm{C}$ en anaerobiosis en placa, luego se aisló las bacterias ácidas lácticas mediante el método de estriado, para preparar las soluciones a ser aplicadas en las papayas.

Para acondicionar las muestras se clasificaron las papayas por tamaño y peso, información necesaria para controlar la pérdida de peso durante los 0,10 y 14 días. Se desinfectó las papayas con agua clorada a $60 \mathrm{ppm}$ para posteriormente iniciar la aplicación de la solución BAL.

Luego, se utilizaron diferentes concentraciones de BAL $(0 \% 5 \%, 10 \%)$, mediante aspersión, se roció las papayas con $10 \mathrm{ml}$ de solución. Se dejó en reposo las muestras entre 15 a 20 minutos temperatura ambiente, para luego ser almacenados en un lugar limpio y libre de impurezas.

Las muestras fueron controladas al día 0,7 y 14 ; cuantificando los cambios que se iban generando en el transcurso del tiempo.

La valoración física de la fruta en los diferentes tratamientos se llevó a cabo bajo los requerimientos de la NTE INEN 1756 [15], se evidenció que la fruta está limpia, entera, bien desarrollada, sana, consistente, fresca, sin humedad exterior anormal, con la forma, color, aroma y sabor típicos de la variedad. El pedúnculo y la pulpa deben estar intactos y firmes.

Las variables químicas que se evaluaron entre ellas el pH se realizó mediante un potenciómetro digital, calibrado con solución buffer de $\mathrm{pH}$ 4,0 y 7,0. Tomando en cuenta lo descrito en el método AOAC 981.12 [16], la acidez titulable se determinó según lo descrito por la NTE INEN-ISO 750 [14], los sólidos solubles fueron determinados mediante lectura directa sobre el refractómetro digital a $25{ }^{\circ} \mathrm{C}$, aplicando la NTE INEN-ISO 2173 [17]

El análisis sensorial lo realizaron 20 panelistas no entrenados, se proporcionó una muestra de cada tratamiento codificados aleatoriamente, se entregó su respectiva hoja para determinar las cualidades organolépticas del mejor tratamiento, se evaluaron los siguientes atributos.

La cuantificación del atributo aroma se realizó mediante la escala hedónica con 4 variaciones: 1 Desagradable, 2 poco agradable, 3 agradable y 4 Muy agradable, que permitió identificar el olor característico de las papayas en las muestras en estudio.

El atributo color se realizó aplicando la escala según el requerimiento general de las frutas, en este caso particular papaya, establecida en la NTE INEN 1756 [15], en una escala de 1 Opaco y 4 Muy intenso.

El flavor, teniendo en cuenta la importancia que 
representa en las frutas, fue evaluado mediante escala hedónica de 1 Desagradable, 2 Poco agradable, 3 Agradable y 4 Muy agradable.

La textura fue analizada mediante la escala hedónica 1 Muy suave, 2 Suave, 3 Duro y 4 Muy duro.

El grado de aceptabilidad fue evaluado también aplicando el método de la escala hedónica, bajo las siguientes descripciones, Me Disgusta, Ni me Gusta Ni me Disgusta, Me Gusta, Me Gusta Mucho.

\section{IV.RESULTADOS}

En la tabla I, se evidencian los valores iniciales de las variables químicas en la papaya luego de ser cosechadas y superada la evaluación física de acuerdo a la NTE INEN 1756 [15], estos valores sirvieron con referencia para determinar la variación en la fruta, en las diferentes aplicaciones de las BAL. Además, el valor de las variables químicas del mucilago de cacao luego de 24 horas de fermentación y previo al aislamiento de las bacterias.

Tabla I. Variables químicas iniciales de las materias primas.

\begin{tabular}{cccc}
\hline & \multicolumn{2}{c}{ PARÁMETROS } & INICIALES \\
& $\mathrm{pH}$ & Acidez $\%$ & ${ }^{\circ}$ Brix \\
Mucílago & 3,55 & 1,33 & $19.25^{\circ}$ \\
Papaya & 5.63 & 0.35 & $10.1^{\circ}$ \\
\hline
\end{tabular}

4.1Análisis físico- químicos de la papaya luego de la aplicación de las BAL

En la tabla II, se puede observar que existió diferencias significativas entre tratamientos $(\mathrm{p} \leq 0,05)$, el
T4 (5\% BAL; 0 Días) presentó los valores más altos de acidez y ${ }^{\circ}$ Brix; mientras que el T9 (10\% BAL; 14 Días) presentó el valor más alto de $\mathrm{pH}$.

Tabla II. Valores promedio de $\mathbf{p H},{ }^{\circ}$ Brix y acidez en la conservación de la papaya con aplicación de bacterias ácidos lácticas provenientes del mucilago de cacao.

\begin{tabular}{cccc}
\hline Tratamientos & $\mathbf{p H}$ & ${ }^{\circ}$ Brix & Acidez \\
\hline $\mathbf{T 1}$ & $5,63 \mathrm{a}$ & $10,1 \mathrm{c}$ & $0,35 \mathrm{~d}$ \\
$\mathbf{T} 2$ & $6,03 \mathrm{ab}$ & $8,37 \mathrm{~b}$ & $0,27 \mathrm{c}$ \\
$\mathbf{T 3}$ & $7,13 \mathrm{bcd}$ & $7,20 \mathrm{a}$ & $0,09 \mathrm{a}$ \\
$\mathbf{T 4}$ & $5,33 \mathrm{a}$ & $10,27 \mathrm{c}$ & $0,36 \mathrm{~d}$ \\
$\mathbf{T 5}$ & $6,07 \mathrm{ab}$ & $8,2 \mathrm{~b}$ & $0,27 \mathrm{c}$ \\
$\mathbf{T 6}$ & $7,50 \mathrm{~d}$ & $7,37 \mathrm{a}$ & $0,12 \mathrm{a}$ \\
$\mathbf{T 7}$ & $5,53 \mathrm{a}$ & $10,2 \mathrm{c}$ & $0,34 \mathrm{~d}$ \\
$\mathbf{T}$ & $6,27 \mathrm{abc}$ & $8,3 \mathrm{~b}$ & $0,19 \mathrm{~b}$ \\
$\mathbf{T 9}$ & $7,27 \mathrm{~cd}$ & $7.00 \mathrm{a}$ & $0,09 \mathrm{a}$ \\
Promedio & 6,31 & 8,56 & 0,23 \\
C.V & 6,31 & 2,27 & 5,7 \\
\hline
\end{tabular}

Los valores de $\mathrm{pH}$ descritos en esta investigación son similares [12], en su estudio de aplicación de películas comestibles en la papaya en el cual obtuvo valores de $\mathrm{pH}$ entre 4.20 a 5.50; mientras que [18], presentaron resultados de 5.1 a 5.4. En la Figura 1 se observa la variación de $\mathrm{pH}$ en al tiempo transcurrido, se visualiza que existió un ligero descenso a los 14 días cuando se aplicó $10 \%$ de BAL, mientras que con $0 \%$ y $\%$ de BAL, este valor aumentó. Dicho aumento se debe posiblemente a la reducción de la actividad metabólica, la disminución de esta actividad es provocada por la menor difusión del oxígeno, tal como lo afirma [19], otro criterio [20], indica que el aumento del $\mathrm{pH}$ en las papayas luego de 8 días de almacenamiento está relacionado con el efecto tampón de compuestos, que se producen en respuesta a la mayor acidez que puede causar reacciones adversas a los frutos, tales como cambios en el sabor. 


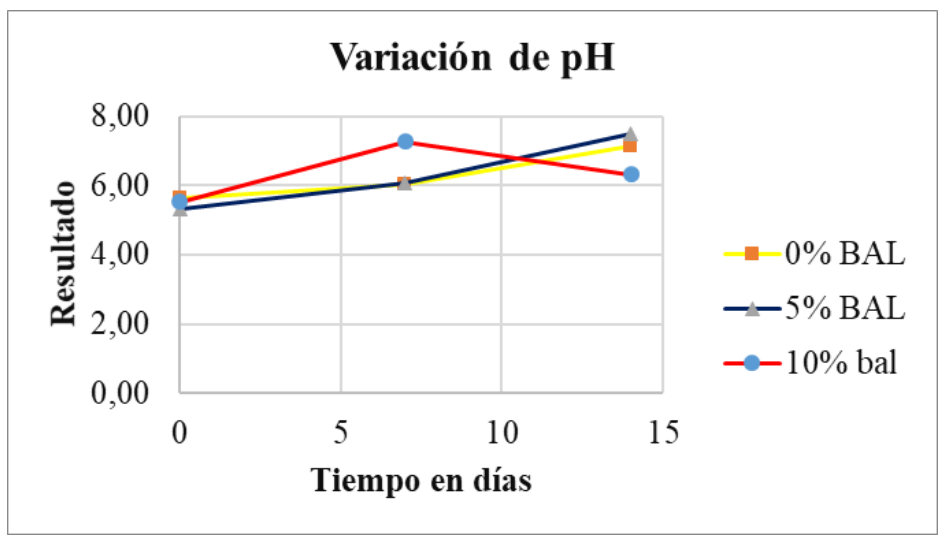

Figura 1. Variación de pH en la conservación de la papaya con aplicación de bacterias ácidos lácticas provenientes del mucilago de cacao CCN-51.

De acuerdo con el Andeva, en la variable ${ }^{\circ}$ Brix de la conservación de la papaya con bacterias ácido lácticas proveniente de mucilago de cacao CCN51 existió diferencia significativa; según la prueba de Tukey $(\mathrm{P} \leq 0,05)$, el T4 (5\% BAL; 0 Días) obtuvo el valor más alto con $10.27 \%$ y el T9 (10\% BAL; 14 Días) presentó el valor más bajo con $7.00 \%$.

Los resultados obtenidos son inferiores a los de [12], quien en su investigación arrojó resultados de $11.00 \%$ a $16.65 \%{ }^{\circ}$ Brix. De acuerdo a lo establecido por [21], puede existir un descenso en los sólidos solubles durante el almacenamiento, que se justifica por el consumo de sustratos en el metabolismo respiratorio de la fruta.

En lo referente a acidez se puede observar que con $0 \%$ de BAL, existió una disminución en el valor de acidez en función al tiempo, mientras se puede identificar un aumento similar al 5\% y $10 \%$ de BAL. Comportamiento similar fue observado por [11], en una muestra control de papaya. El aumento de la acidez se explica por la formación de ácido galacturónico en el proceso de degradación de la pared celular durante la maduración de la papaya. El aumento probablemente se deba a la formación de ácido galacturónico, como resultado de la degradación de las pectinas, ya que al ser el período de maduración de la intensa actividad metabólica, los ácidos constituyen una excelente reserva de energía de la fruta a través de su oxidación en el ciclo de Krebs [20]. Por lo tanto, la liberación de ácidos orgánicos de estas reacciones puede aumentar la acidez.

Los resultados de colorimetría se describen en la tabla 5 , en función a los días de conservación de la papaya.

Tabla III. Valores promedio de colorimetría en la conservación de la papaya con aplicación de bacterias ácidos lácticas provenientes del mucilago de cacao CCN-51.

\begin{tabular}{|c|c|c|c|c|c|c|c|c|c|}
\hline \multirow{3}{*}{$\begin{array}{l}\text { Días de } \\
\text { conserv } \\
\text { ación }\end{array}$} & \multicolumn{9}{|c|}{ Porcentaje de Bacterias Ácido Lácticas } \\
\hline & $0 \%$ & $5 \%$ & $10 \%$ & $0 \%$ & $5 \%$ & $10 \%$ & $0 \%$ & $5 \%$ & $10 \%$ \\
\hline & & Tinte & & & Croma & & & $\Delta \mathrm{E}$ & \\
\hline 0 & -76.77 & -72.18 & -75.80 & 27.99 & 23.75 & 24.11 & 44.68 & 42.26 & 44.22 \\
\hline 7 & -75.80 & -10.51 & 33.20 & 30.40 & 70.21 & 80.18 & 44.22 & 83.75 & 113.53 \\
\hline 14 & 62.10 & 12.81 & 36.75 & 307.47 & 149.15 & 136.92 & 314.13 & 160.01 & 149.51 \\
\hline
\end{tabular}

Como se observa en los valores promedios, cuando se llegó al día 14 de conservación, en el aspecto Tinte al igual que la variable Croma, cuando se aplicó 0\% de BAL, el valor fue mayor con 62.10. Estas mediciones de color se pueden usar como una forma indirecta de estimar su cambio en los productos alimenticios, ya que es más simple y rápido que el análisis químico. Los parámetros de color medidos instrumentalmente se han utilizado para describir el deterioro visual del color y en el control de calidad de la fruta [22]; generalmente, frutas como la papaya, se consumen con su máxima calidad organoléptica, que se presenta cuando la fruta ha alcanzado por completo el color amarillo o naranja (característico de madurez), pero antes del ablandamiento 
excesivo. Por tanto, el color es la característica externa más importante en la determinación del punto de maduración y de la vida pos cosecha y un factor concluyente en la decisión de compra por parte de los consumidores. El color amarillo es el resultado de la degradación de la clorofila, así como de la síntesis de cromoplastos [23].

\subsection{Análisis sensorial}

El análisis de Kruskall Wallis dio como mejor tratamiento al T9 que corresponde a la aplicación de $10 \%$ de bacterias ácido lácticas y 14 días de conservación, pues los catadores determinaron que entre las características de la fruta en comparación a la testigo (sin aplicación de las bacterias ácido lácticas), hubo repotenciación del sabor, color uniforme, olor a fruta fresca, en cambio la testigo se encontraba ya sobre-madura, olor no agradable y apariencia muy desagradable.

En cuanto a la aceptabilidad, los valores del T9 fueron muy superiores, tal como se observa en la Figura 2, que el tratamiento aplicado influye en la aceptabilidad de la papaya.

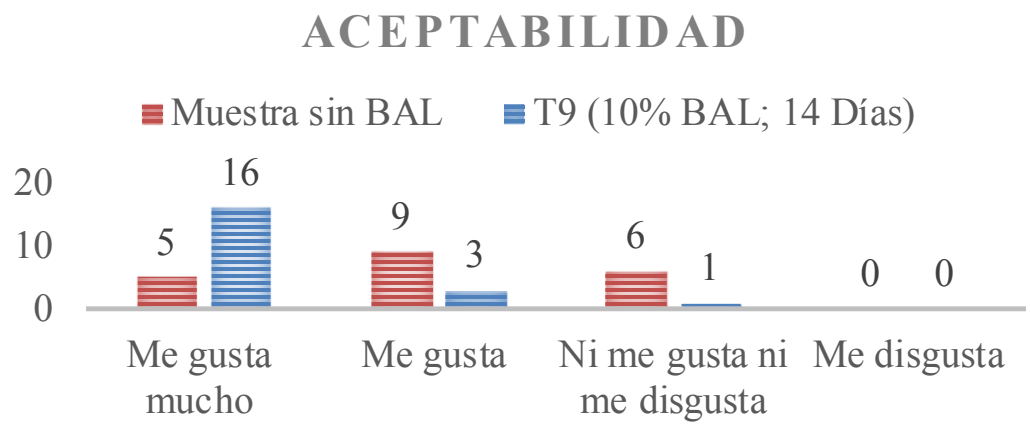

Figura 2. Comparación de aceptabilidad de T9 (10\% BAL; 14 Días) frente a muestra sin adición de BAL

\section{V.CONCLUSIONES}

1.Las características físico-químicas evaluadas indicaron que según la prueba de Tukey $(\mathrm{P} \leq 0,05)$, existieron diferencias significativas a nivel de $\mathrm{pH},{ }^{\circ}$ Brix y acidez; destacando que cuando se aplicó $10 \%$ de BAL hubo un ligero descenso del $\mathrm{pH}$ cuando transcurrieron los 14 días de conservación. En cuanto al aspecto de colorimetría se observó que el color de la fruta se mantuvo en niveles adecuados al transcurrir los 14 días.

2.Transcurrido el tiempo de 14 días de conservación, se pudo identificar que el T9 (10\% BAL; 14 Días) mantuvo mejores propiedades al respecto de los demás tratamientos, esto debido a la aplicación de las BAL, prolongando su tiempo de vida útil.

3.En la parte sensorial, T9 (10\% BAL; 14 Días), presento mejores propiedades organolépticas frente a una muestra sin adición de BAL, pudiéndose entender que las aplicaciones de estas bacterias contribuyen a que las cualidades sensoriales se mantengan e inclusive se repotencien.

\section{REFERENCIAS}

[1]Organización de las Naciones Unidas para la Agricultura y la Alimentación FAO, "Procesamiento de frutas y verduras," Roma, 2014.

[2]E. Rodríguez-Sauceda, "Uso de agentes antimicro- bianos naturales en la conservación de frutas y hortalizas," Ra Ximhai, vol. 7, pp. 153-170, 2011, doi: 10.35197/rx.07.01.2011.14.er.

[3]R. Raybaudi-Massilia, R. Soliva, and O. Martín, "Simposio Iberoamericano de Hortalizas Frescas , 1/ Congreso Nacional de Procesamiento Mínimo de Frutas y Hortalizas , 4 ( 2006 )," 2006.

[4]M. Valle, "Aplicación de recubrimientos comestibles para mantener la calidad de frutillas congeladas," p. 211, 2012.

[5]A. Garcia Figueroa, A. Ayala-Aponte, and M. I. Sánchez-Tamayo, "Efecto de recubrimientos comestibles de Aloe vera y alginato de sodio sobre la calidad poscosecha de fresa," Rev. U.D.C.A Actual. Divulg. Científica, vol. 22, no. 2, 2019, doi: 10.31910/rudca.v22. n2.2019.1320.

[6]K. Córdova and A. Loor, "Prolongación de la vida útil de la papaya ( Carica papaya ) en percha por inmersión en soluciones de propóleo en etanol," 2014.

[7]I. M. Brasil, C. Gomes, A. Puerta-Gomez, M. E. Castell-Perez, and R. G. Moreira, "Polysaccharide-based multilayered antimicrobial edible coating enhances quality of fresh-cut papaya," LWT - Food Sci. Technol., vol. 47, no. 1, pp. 39-45, 2012, doi: 10.1016/j. lwt.2012.01.005.

[8]Z. Kalvatchev, D. Garzaro, and F. Guerra Cedezo, 
"Theobroma cacao L.: Un nuevo enfoque para nutrición y salud," Rev. Agroaliment., vol. 4, no. 6, pp. 23-25, 1998.

[9]S. Vasquez, H. Suárez, and S. Zapata, "Utilización de sustancias antimicrobianas producidas por bacterias acido lácticas en la conservación de la carne," Rev. Chil. Nutr., vol. 36, no. 1, pp. 64-71, 2009, doi: 10.1097/ PHH.0000000000000678.

[10]R. Rivera-Rebollar, S. Cabrera-Calderón, A. Lira-Vargas, M. Trejo-Márquez, and S. Pascual-Bustamante, "Efecto de recubrimiento de carboximetilcelulosa adicionado con extracto de epazote en el control de hongos postcosecha de papaya, jitomate y chile," Investig. y Desarro. en Cienc. y Tecnol. Aliment., vol. 1, no. 2, pp. 379-384, 2016.

[11]A. Sañudo, J. Siller, T. Osuna, D. Muy, G. López, and J. Labavitch, "Control de la maduración en frutos de papaya (Carica papaya L.) con 1-metilciclopropeno y ácido 2- cloroetil fosfónico," Rev. Fitotec. Mex., vol. 31, no. 2, pp. 141-147, 2008.

[12]A. Almeida-Castro, J. Reis-Pimentel, D. Santos-Souza, and T. Vieira, "Estudio de la conservación de la papaya (Carica papaya L.) asociado a la aplicación de películas comestibles," Rev. Venez. Cienc. y Tecnol. Aliment., vol. 2, no. 1, pp. 49-060, 2011.

[13]A. Jimenes-Trujillo, "Recubrimiento Comestible a Base de Aloe Vera (Aloe barbadensis miller) para Papaya (Carica papaya) Y Guayaba (Psidium guajava) Como Alternativa de Alimentos de IV Gama," Universidad Técnica del Norte, 2017.

[14]Instituto Ecuatoriano de Normalización, "NTE INEN-ISO 750:2013 Productos Vegetales y de Frutas - Determinación de la Acidez Titulable (IDT)," 2013. [15]Instituto Ecuatoriano de Normalización., "NTE INEN 1756. Frutas Frescas. Papaya. Requisitos," Ecuador, 1990.

[16]A. International, "AOAC: Official Methods of Analysis."

[17]Instituto Ecuatoriano de Normalización, "Norma Técnica Ecuatoriana NTE INEN-ISO 2173:2013," 2013.

[18]A. Miranda, A. Alvis, and G. Arrazola, "Efectos de dos recubrimientos sobre la calidad de la papaya (Carica papaya) variedad tainung," Temas Agrar., vol. 19, no. 1, pp. 7-18, 2014.

[19]L. Konda et al., "InfluêncIa da atmosfera modIfIcada por fllmes plástIcos sobre a qualIdade do mamão armazenado sob refrIgeração 1," 2006.

[20]A. Castricini, "Aplicação de Revestimentos Comestíveis para Conservação de Mamões (Carica papaya L.) 'Golden,"' UNIVERSIDADE FEDERAL RURAL DO RIO DE JANEIRO, 2009.
[21]M. Mata, M. del C. Vásquez, N. Higinio, and D. Hernandéz, "Estudio comparativo de bio-recubrimientos a partir de Manihot esculenta y Phaseolus vulgaris empleadas como recubrimiento en uvas moradas," Rev. Ciencias Ambient. y Recur. Nat., vol. 2, no. 5, pp. 1125, 2016.

[22]M. Maskan, "Microwave/air and microwave finish drying of banana," J. Food Eng., vol. 44, no. 2, pp. 71-78, 2000, doi: 10.1016/S0260-8774(99)00167-3.

[23]R. Torres, E. Montes, O. Pérez, and R. Andrade, "Relación del color y del estado de madurez con las propiedades fisicoquímicas de frutas tropicales," Inf. Tecnológica, vol. 24, no. 3, pp. 51-56, 2013, doi: 10.4067/S0718-07642013000300007.

\section{RESUMEN CURRICULAR}

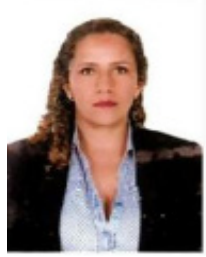

Cyntia Erazo Solórzano, Ingeniero Agroindustrial, área de conocimiento: Agroindustrias. Magíster en Gestión de la Producción, área de conocimiento: Producción. Master en Prevención de Riesgos Laborales, área de conocimiento: Ciencias Sociales y Jurídicas. Cursando: Doctorado en Ingeniería Agraria, Alimentaria, Forestal y de Desarrollo Rural Sostenible.

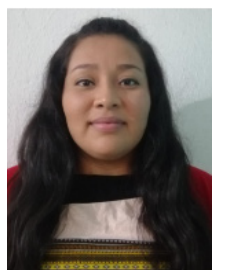

Diana Sal azar Daza, Ingeniera en Alimentos, graduada en septiembre del 2020 en la Universidad Técnica Estatal de Quevedo.

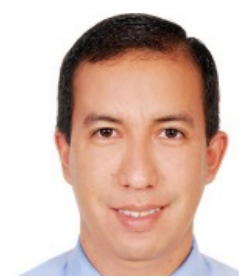

Jaime Vera Chang, Ingeniero Agropecuario graduado en la Universidad Técnica Estatal de Quevedo. Magíster en Procesamiento de Alimentos en la Universidad Agraria del Ecuador. Miembro del Comité de Investigación de la Facultad de Ciencias Pecuarias.

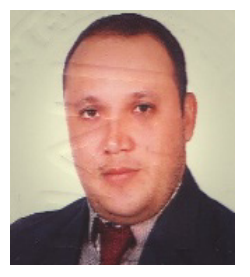

Diego Tuárez García, Ingeniero Agroindustrial en la Universidad Técnica Estatal de Quevedo. Magíster en Gestión de la Producción, área de conocimiento: Producción. Master en Prevención de Riesgos Laborales, área de conocimiento: Ciencias Sociales y Jurídicas. Cursando: Doctorado en Ingeniería Agraria, Alimentaria, Forestal y de Desarrollo Rural Sostenible. 